\title{
Standardization of System Integrated Solutions in Warehouse Management Systems (WMS) Implementations
}

\author{
Natesan Andiyappillai \\ Senior Business Analyst \\ NFI Industries, 1005 Laurel Oak Rd, Voorhees \\ $\mathrm{NJ}, 08043$, US
}

\begin{abstract}
Logistics plays an important role in a Supply Chain to ensure the materials are flowing thru the entire supply chain channel seamlessly and efficiently. And, the Warehouse Management Systems (WMS) help facilitating that in a supply chain, being WMS one of the key IT Logistics Systems. Due to globalization and dynamic market and consumer behavior, WMS has been integrated with the external systems for accurate and timely data communication and effective business collaboration. Managing these systems integrations become complex and tedious when the business runs on different industry verticals and on different platforms. Hence, it becomes very important and necessary for the Logistics service providers to standardize the system integrated solutions when it comes to WMS implementations. This article explains the feasibility of standardizing the system integrated solutions in WMS Implementations and the pros
\end{abstract}

and cons of the same by conducting a case study in a leading Logistics and Supply Chain company.

\section{Keywords}

Warehouse Management Systems (WMS), Systems Integration and Standardization

\section{INTRODUCTION}

Supply chain is a channel to bring together all the entities involved in a business to be able to reduce the life cycle of a product from the source to destination thus reducing costs. This concept is applicable to any industry that has multiple business partners working in a dynamic environment. Getting the materials delivered from the supplier to consumer quicker is an important objective of a supply chain. A typical supply chain model is shown below to understand the entities involved.

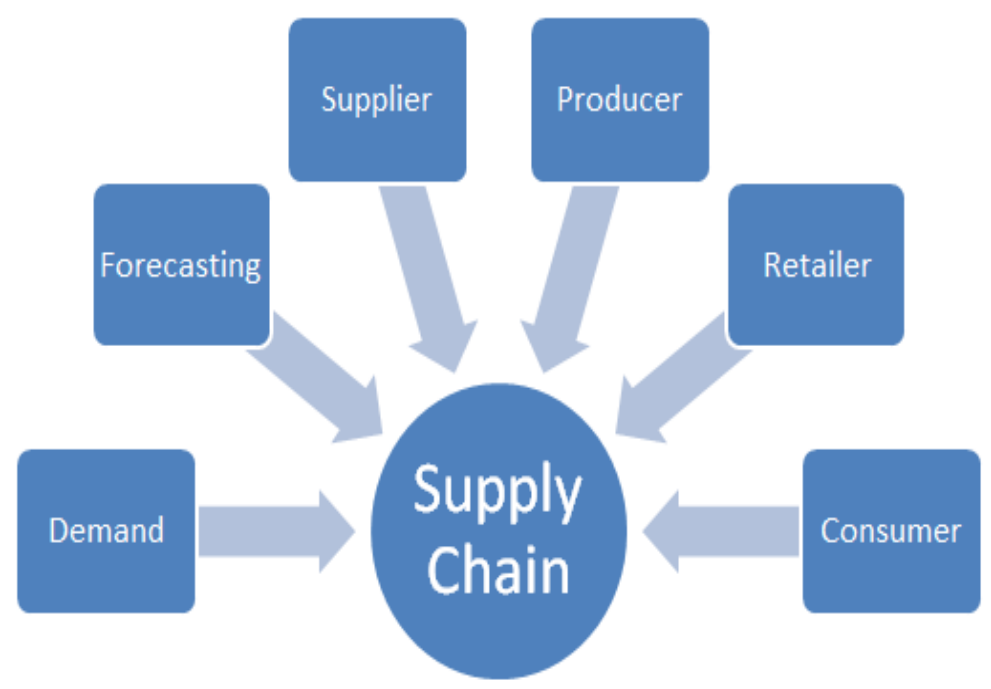

Fig 1: A Typical Supply Chain Model

The more globalized and the more partners or entities involved in a business, the Supply Chain becomes bigger and higher. Hence, the more challenges come to manage in managing the supply chain lean and efficient.

Logistics is a core and integral component in a Supply Chain which helps an enterprise to ensure the delivery of the right product, at right time, at right condition and to the right customer. This also helps the product flow in the backward direction with no business interruptions. Logistics models help the organizations to keep the inventory at optimum level at all times and a typical Logistics model is shown below. 


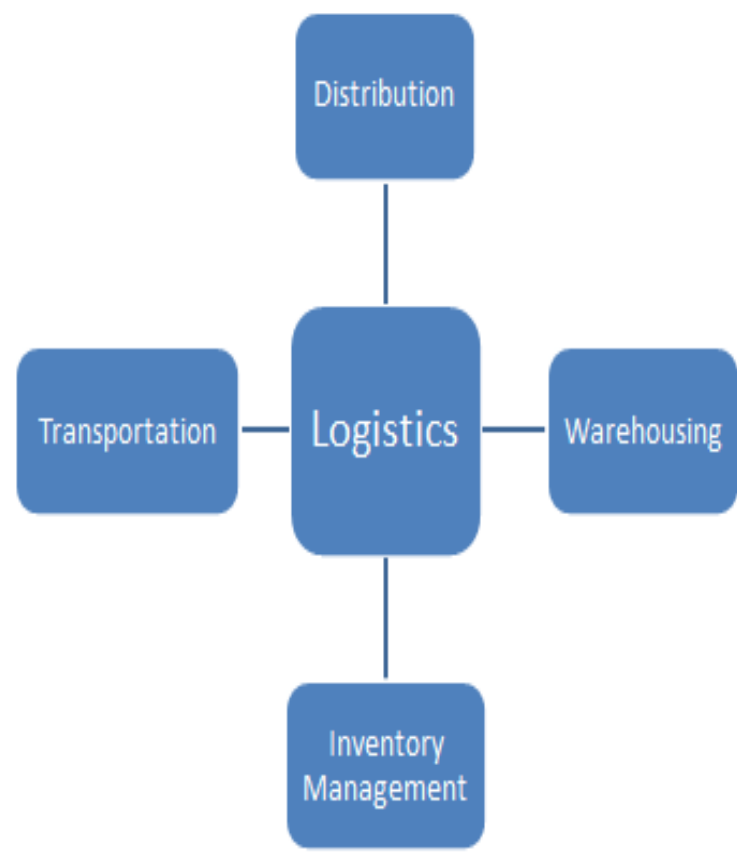

Fig 2. A Typical Logistics Model

The IT systems help the companies to manage and maintain the inventory accurately while fulfilling the customer orders and adhering to customer compliances. And, it is evident that Warehouse Management Systems (WMS) plays a critical role in doing that in the Logistics industry. WMS primarily helps to manage the inventory at a Distribution or Warehouse facility per customer requirements and also helps to perform the value added services as needed.

WMS helps the businesses to communicate and collaborate with all the logistics partners effectively and also real-time when it is integrated with all the necessary external systems or partners. Here comes the Systems integration into place for communicating the right data, at the right time and to the right business partner.

Systems integration is an important milestone in a WMS implementation given the fact that there could be many business partners, different systems, different modes of communication, a variety of data and potentially multiple business cultures. But, it provides the competitive advantage to the business for being able to react to the customer and market very effectively, efficiently and with no time loss.

At the same time, it becomes so complex and heavy for a Logistics service provider to manage all these Systems integrations when the business runs on a variety of industry verticals, different integration platforms and with different WMS applications.

\section{LITERATURE REVIEW}

Managing and optimizing the warehouse space, customer inventory, tracking the inventory movements, identifying the opportunities for process and labor productivity improvement become impossible without the WMS applications and its integrations with the customer and other applications at the current business environment when the business model is so unique and complex.

Dowlatshahi [1] has insisted the importance of integration and has developed a Design For Logistics model to integrate Logistics-related issues (plant location, material management, storage, traffic, packaging, etc.) in the early phases of Product Design process. In this approach, Supply Chain concerns are embedded in interfaces, modelled according to four disciplines: Logistics engineering, Manufacturing Logistics, Design for Packaging, and Design for Transportability.

To carry out the integration of logistics in product design, the consideration of this problem's characteristics is required, both in terms of actors to promote the methods and tools to support it. Moreover, systems engineering is a general approach that encompasses all the appropriate activities to design, develop and verify a system by providing an optimized solution to a client's needs while satisfying all the stakeholders, per Guillerm [2].

Lee and Billington [3] assert that one of the common pitfalls in managing Supply Chain is to overlook inventory, distribution and planning costs during the product-process design. The authors also claim that the product-process design should be evaluated not only in terms of functionality and performance, but also in terms of Design For Supply Chain Management (DFSCM), i.e., costs and serviceability issues.

Rodney et al. [4] served an integrated business process model, which highlights the importance of communication between processes and partners in the supply chain for gaining competitive advantage by optimizing global supply chain efficiency.

Togar et al. [5] established a comprehensive taxonomy of coordination modes, which are logistics synchronization, information sharing, collective learning and incentive alignment to have positive impacts on supply chain performance.

Though there are many researches have been published on the importance of systems integrations in Logistics and Supply Chain, it is very challenging and hard to find if there are any researches performed and articles published in the Standardization of Systems Integration with respect to Warehouse Management Systems (WMS) implementations. 


\section{WMS IMPLEMENTATIONS AND ITS SYSTEMS INTEGRATION}

Implementing Warehouse Management Systems (WMS) helps the businesses run the warehouse and distribution processes in the IT applications. It helps in providing the inventory visibility, fulfilling the customer orders and replenishment requirements, maintaining the customer compliance and performing other ancillary services or activities in the system for traceability.

A successful WMS implementation requires the key components or milestones to be completed per the model shown below in figure 3 and the EDI integration plays a crucial role in getting the communication flow thru the channels.

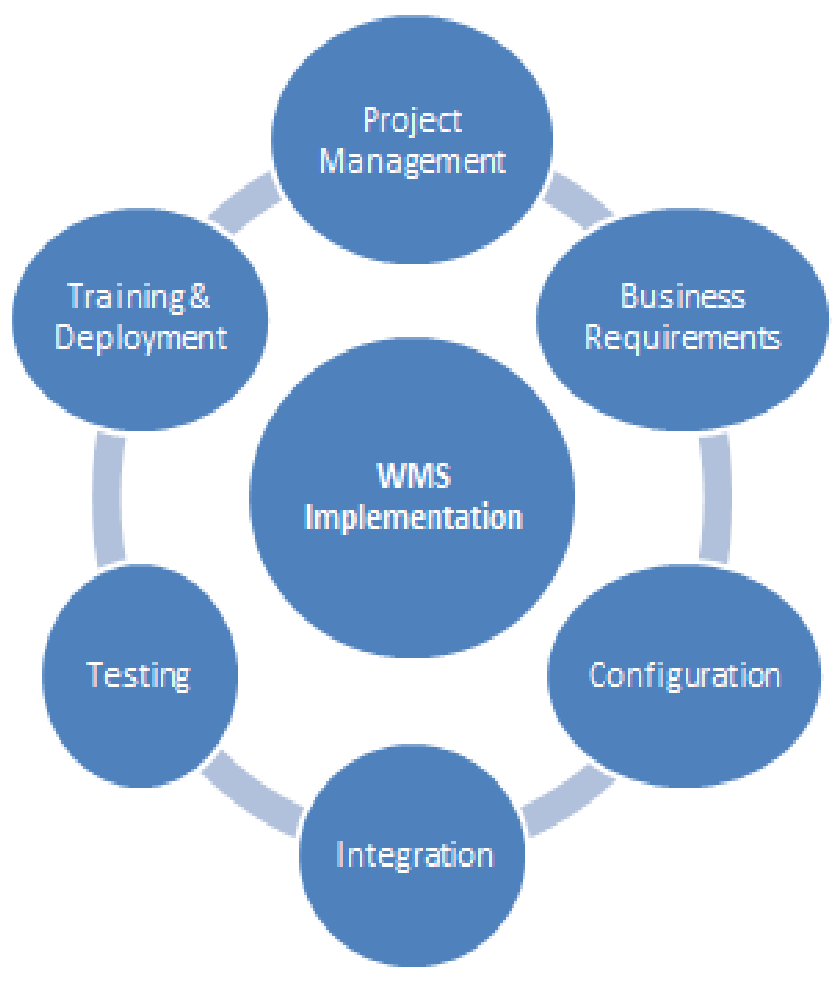

Fig 3. A Typical WMS Implementation model

WMS is often integrated with other external systems such as Customer Host thru EDI Integration systems, also called as Middleware applications. This helps the Logistics and Supply Chain providers to communicate with the customer electronically, with no business interruption and with no manual intervention. And, also helps to receive and get the data real time. The below figure shows the integration of WMS application with the Host system in a typical systems integration environment.

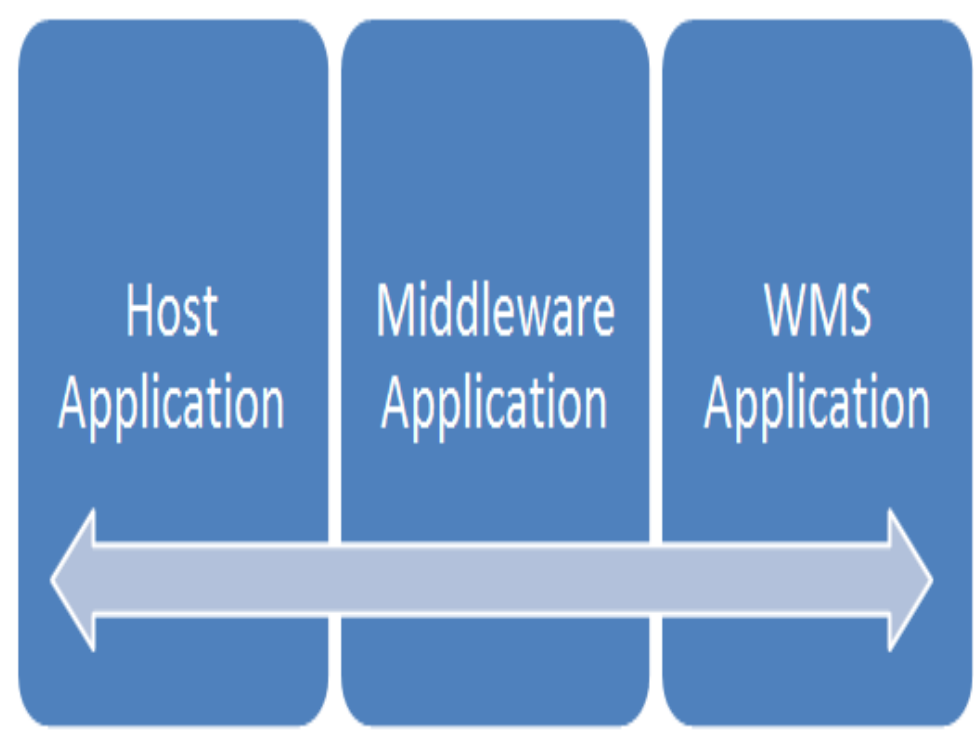

Fig 4. A Typical System Integration Environment in WMS Implementations 
There are many customer Host applications and WMS applications, also termed as Enterprise Resource Planning (ERP) applications, available in the market per industry verticals, domain expertise, modules built and supported. A customer or Logistics service provider generally evaluates the Host system capability against the business requirements and implements the right one for the business.

There are many Middleware applications available too in the market and the companies determine the different factors such as; Systems requirements, product capability \& capacity, product flexibility and product reliability to determine the right product for seamless integration of systems.

\section{A CASE STUDY ANALYSIS}

This case study has been conducted in a leading Logistics and Supply Chain company to understand the Systems Integrated Solutions that are offered in WMS implementations and also to understand the pros and cons of having the Standardization on these Systems integration.

The mode of data collections are; studying and observing the actual systems integrations, collecting information from the project documentations and also discussion with the Subject Matter Experts (SMEs)

As the company Logistics business grows at the rate of about $12 \%$ a year and with the drastic changes to the current market behavior and eventually the potential changes in near future, the company has made significant investments in IT infrastructures lately. Being a leader in the Logistics and Supply Chain industry, the company is using a Tier-1 Middleware application to be able to integrate the Tier-1 WMS application that the company uses with any Customer Host applications.

When it comes to the Systems integration, the company groups the components involved in this Systems integration process into four primary categories based on the impact of each of these components on the Integration and they are listed in the below figure. Understanding the customer requirement for each of these components and getting them mapped appropriately is a key to the Electronic Data Interchange (EDI) integration.

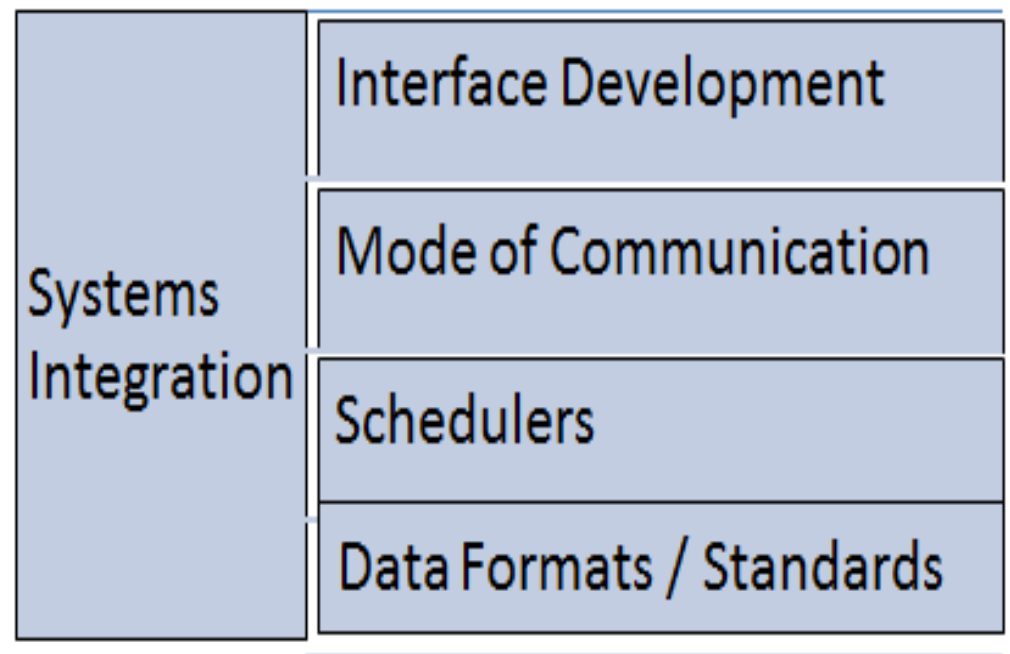

Fig 5. The Primary Categories in Systems Integration

The company uses a number of EDI transactions or messages between the Host and the WMS thru EDI integration systems based on the customer or business requirements. The primary and key data exchanged between these two systems are shown in the below chart and this depicts the responsible party for each of these interface;

\begin{tabular}{|c|c|c|c|}
\hline S.No & Data Exchange / Interface Name & Source & Destination \\
\hline 1 & Customer Item Master Data & Host & WMS \\
\hline 2 & Purchase Order Data & Host & WMS \\
\hline 3 & Receipt confirmation Data & WMS & Host \\
\hline 4 & Shipping Order Data & Host & WMS \\
\hline 5 & Shipment Confirmation Data & WMS & Host \\
\hline 6 & Inventory Advice & WMS & Host \\
\hline 7 & Inventory Adjustments & WMS & Host \\
\hline
\end{tabular}

Fig 6. The Primary Data Exchange / Communication between Customer and Host

The EDI data is driven from the Host to WMS for Inventory management, Order Fulfillment, Customer Compliance etc and WMS reports back to the Host with the updates for those corresponding requests. Hence, the company understands that it is critical to integrate the WMS application with the Host system for seamless and timely data communication flow between them.

When both the systems are integrated, there are different EDI transactions that flow between them for various data exchange and communication as explained above. And, the company realized that it becomes very challenging to develop and 
maintain these Integrations when the business is running different platforms/architectures. It also adds up much more IT development and maintenance costs for the Logistics \& Supply chain service providers when there are multiple customers/businesses integrated with WMS in different platforms/architectures. And, when there are additional services offered such as Reporting, Billing and Customer Compliance for the customer/business, both the costs go up exponentially even further. This had become a huge bottleneck for the company in the Systems Integration offerings.

After doing necessary research and analysis by the experts at the company, it had realized that it is important for the Logistics service providers to standardize the integrated solutions at WMS Implementations to alleviate the challenges or issues at Systems Integration. The company also realized that the Standard integrated solutions will not only help savings in IT costs and quicker implementation in a big way but also help to standardize the Logistics processes across the business enterprise.

It was determined to find out the factors that are contributing on the Standardized Systems Integrated Solutions and bring the uniformity to each of these factors and build a templatized (Standardized) solution accordingly.

The company had identified the Key factors that are impacting the Standardized System Integrated Solutions and the changes that were needed on each of these corresponding factors were researched and analyzed by the company expertise and are detailed below;

i) Mode of communication AS2 communication with the customer to transfer or exchange the data secure, reliable and efficient.

ii) EDI file format/version X12 format with the customer for business documents and data exchange.

iii) EDI frequency/timings 30 minutes lead time from the time the data is received from the customer Host and have the data sent to WMS.30 minutes lead time from the time the operational process is completed in WMS and the corresponding data sent to customer Host.sending the Inventory snapshot to Customer Host once a day at 4 am, ideally when no operations are using the WMS.

iv) Standard templates built a EDI mapping template based on the industry/business requirements and develop the each interface as shown in figure 6 accordingly.

v) Customer agreement and alignment Crucial to make the customer understand this Standardized System Integrated Solutions and make them comply with these Integration solutions on WMS implementation projects.

vi) Impact on Ancillary tools Changes to the ancillary tools such as Reporting and Billing in alignment with the standards.

vii) EDI Errors NotificationEDI monitors to report any EDI errors to the necessary business partnersEDI acknowledgements for the business partners to see the status of an EDI.
The company had started seeing the Benefits of using the Standardized Systems Integrated Solutions in WMS implementations and they are listed below;

1. Easy maintenance

$>$ As this is a standardized solution and template based pre-built systems integration, it is easy to maintain these integrations. The company sees the maintenance effort metrics with close to $35 \%$ improvements.

2. Faster deployment

$>$ The lead time to deploy this model in a WMS implementation has drastically reduced and the company has witnessed this at about $40 \%$ reduction.

3. Standard processes

$>$ This helps the organization to run the standard IT WMS processes across the enterprise thus eventually helps the standardization in operational procedures as well.

4. Automated testing

$>$ The company had got the opportunity in deploying the Automated testing process in the WMS implementation projects due to this standard integration solutions and it reduces the testing effort by as high as $60 \%$.

While the company is enjoying the benefits in using the Standardized Systems Integrated Solutions, there are some disadvantages as well in using this model and they are;

1. Customers inflexibility

$>$ Though most of the customers agree to comply with this model on systems integration, some of them are hesitant and unable to accommodate into.

\section{Huge impact on changes}

$>$ As part of continuous improvements to these Integrations, the changes are made to the Standardized solutions and this requires considerable amount of time in design, development, testing and deployment with the changes.

In general, Logistics and Supply Chain providers are working towards a model where the Warehouse Management Systems Implementations are done Better, Faster and Cheaper. There are many initiatives being taken by them to align the business towards that model and Standardized Systems Integrations is always one of the key and important strategic initiatives as this impacts the customer directly and very significantly.

\section{CONCLUSION}

Logistics \& Supply Chain Systems help businesses to manage and maintain the customer inventory accurately while performing the logistics and supply chain services. Warehouse Management Systems (WMS) is one of the Logistics Systems that is often integrated with other external systems, primarily with the customer Host application for EDI (Electronic Data Interchange) data exchange and communication as per the business requirements. While the EDI integration helps the Logistics service providers to be competitive in the market, it poses huge challenges in maintaining these systems integrations when the business supports multiple customers, multiple industry verticals and running multiple EDI platforms. This case study has revealed the systems integration plays a key role in the business success but poses challenges to maintain them for the long run. The company is being greatly benefited thru the Standardization of the 
Systems Integrated Solutions in WMS implementations though there are few challenges in deploying them in the current market behavior.

\section{REFERENCES}

[1] S. Dowlatshahi, "The role of logistics in concurrent engineering," International Journal of Production Economics, vol. 44, no. 3, pp. 189-199, 1996.

[2] R. Guillerm, "Integration of dependability in system engineering processes," Ph.D. Thesis, University of Toulouse Paul Sabatier, 2011.

[3] H. L. Lee and C. Billington, "Managing supply chain inventory pitfalls an opportunity," Sloan Management Review, vol. 33, no. 3, pp. 65-73, 1992.

[4] Rodney McAdam and Daniel McCormack. Integrating business processes for global alignment and supply chain management, Business Process Management Journal, Vol. 7 No. 2, 2001, 113-130

[5] Togar M. Simatupang, Alan C. Wright and Ramaswami Sridharan. The knowledge of coordination for supply chain integration, Business Process Management Journal, Vol. 8 No. 3, 2002, 289-308A
[6] G.C.Stevens, Integrating the supply chain, International Journal of Physical Distribution and Materials Management, No., 8 (1989), pp. 3-8

[7] Simichi-Levi, D., Kaminsky, P., Samichi-Levi, E., 2000. Designing and Managing the Supply Chain. Concepts, Strategies and Case Studies, McGrawHill/Irwin, Boston, 243-244.

[8] P.RomanoCo-ordination and integration mechanisms to manage logistics processes acrosssupply networks, Journal of Purchasing and Supply Management, Vol. 9, Issue, 3 (2003), pp. 119-134

[9] Poirier Ch.C., 1999.Advanced Supply Chain Management. Berrett-Koehler Publishers, San Francisco, 23-41.

[10] B. HentschelR.Domański,M.Adamczak,P.Cyplik,L.Hada s, M.Kupczyk, Z. PruskaRanking of integration factors within supply chains of forward and backward types recommendations from researches, LogForum, 11 (2) (2015), pp. 161-169

[11] A.T. Kearney, Integrating the supply chain, Management Reports, No.42, 1994 